Part of Journal of Research of the National Bureau of Standards, Volume 25, July 1940

\title{
ELECTRODIALYTIC ESTIMATION OF ASH AND OF ACIDIC AND BASIC GROUPS IN TEXTILE FIBERS
}

\author{
By Arnold M. Sookne, Charles H. Fugitt, and Jacinto Steinhardt ${ }^{1}$
}

\section{ABSTRACT}

The method of combustion, usually employed in the determination of the ash of textile fibers, yields results which acquire significance in terms of equivalents only when an estimate of the composition of the ash can be made. It is shown in the present paper that the hydrogen-ion equivalence of the cationic ash of fibers may be obtained directly, without ignition, by slight modifications of simple electrodialytic procedures hitherto applied to solutions. The content of any given diffusible anion in the fiber may be similarly determined. A simple extension of the method which permits the quantitative determination of the acidic and basic groups of fibers (and of other nondiffusible substances) consists in engaging these groups with suitable cations or anions, which are then estimated by electrodialysis.

Examples are given of the application of the method to samples of dewaxed and depectinized cotton. In both cases the results are shown to correspond with the capacity of the fibers to combine with acid. Examples are also given of electrodialytic determinations of the cations of wool fibers, and in samples of wool cloth at several stages in processing subsequent to the carbonizing process. A comparison of these results with the ash obtained gravimetrically after combustion permits the calculation of the average equivalent weight of the constituents of the ash, and indicates that most of the ignited residue of wool consists of sulfates. Since sulfates are known not to be present to any appreciable extent in washed defatted root wool fibers which have not undergone carbonizing, the presence of this anion in the ash of these fibers must be attributed to the oxidation of part of the sulfur of the wool during combustion.

III. Results and discussion

1. Cotton

2. Wool

3. Electrodialytic determination of acidic and basic groups of fibers and other nondiffusible materials _.

IV. References

\section{INTRODUCTION}

Considerable practical and theoretical interest attaches to the estimation of the ash of textile fibers. The method of combustion usually employed is time-consuming and yields values which acquire significance in terms of equivalents only when an estimate can be made of the composition of the igneous residue. In addition, this method may sometimes give values which do not accurately represent the

\footnotetext{
1 Research Associates at the National Bureau of Standards, representing the Textile Foundation.
} 
inorganic constituents in the unburned fiber. Thus the ignition of wool results in the formation of sulfate from the oxidation of part of the organic sulfur of the amino acid, cystine, which constitutes an appreciable part of this protein. Consequently, the ash of wool is heavier than it would be if all of the inorganic bases combined with it were found as carbonates or oxides.

The method of electrodialysis used by Joseph and Stadie [1] ${ }^{2}$ for the determination of total cations and chloride in blood has been found to be of value for the estimation of the equivalence of the cationic ash of textile fibers (the term "cationic ash" in this paper signifies the total content of the cations of bases, whether free, or combined as salts of acids or of the acid groups of the fibers). ${ }^{3}$ This method permits the direct estimation of the hydrogen-ion equivalence of the cationic ash; in addition, it may be extended to include the estimation of specific anions, such as sulfate, which are important in the control of textile finishing processes. Unlike the combustion method, electrodialysis has preparative as well as analytical value, since the samples used in analysis may be recovered, freed of most of their ash, at the end of the determination.

Besides describing the procedure which may be employed with a number of textile fibers and demonstrating the accuracy of the results obtained, the present paper also suggests simple extensions of the procedure which render it applicable to the direct determination of the acidic and basic groups of a wide variety of materials, including fibers.

\section{METHOD}

In the present investigation, the method of Joseph and Stadie was followed with two modifications: a) The addition of dilute acid to the sample to be dialyzed aided in the liberation of cations combined with the fibers, and greatly shortened the time required for their recovery at the cathode. b) The formation of a reliable seal between the Cellophane membranes and the sides of the dialysis tubes was considerably expedited by the substitution of a commercial cellulose nitrate cement, ${ }^{4}$ for the collodion employed by Joseph and Stadie. A diagram of the apparatus employed, copied from the original article, is given in figure 1. The application of a potential difference across the electrodes brings about the migration of cations to the mercury cathode, where they are discharged and form amalgams. Subsequent mixing of the amalgam with the standard solution of hydrochloric acid above the mercury causes a reduction in its titer which corresponds to the hydrogen-ion equivalence of the cationic ash. The titers of the original and final solutions were measured with a $0.02 M$ solution of sodium hydroxide, using bromcresol purple as the indicator. When chloride is among the anions present, it is discharged at the anode unless, as in Joseph and Stadie's method, a suitable reducing agent is added to the anode chamber in order to prevent this. When sulfate is present, oxygen is evolved and sulfate accumulates in the anode chamber.

3 Figures in brackets indicate the literature references at the end of this paper.

3 The term is equivalent to the conventional expression "total base" used by Joseph and Stadie in the paper cited, and by biochemists generally.

Duco cement, made by E. I. DuPont de Nemours \& Co., was employed. 
The quantity of sulfate in the sample may then be determined gravimetrically by precipitation as barium sulfate.

In the method actually employed, a sample of purified cotton, wool, or silk weighing between 0.5 and $1 \mathrm{~g}$ was placed in the sample chamber, and soaked in a dilute solution of hydrochloric acid for an hour, after which the sample was electrodialyzed for 2 hours. A resistance of $1,000 \mathrm{ohms}$ in series with the electrodes gave an initial passage of current of about 100 milliamperes, which diminished rapidly as the removal of ions progressively raised the resistance of the dialysis chamber. The accumulation of bubbles of gas on the membranes is avoided by occasionally tapping the outer glass tube. With cotton, identical results for the cationic ash were obtained when $0.02 M$ or $0.15 M$ solutions of hydrochloric acid were used for the soaking treatment. Longer periods of electrodialysis did not appear to increase the effectiveness of recovery of the cationic ash of cotton. With wool, however, slightly more consistent results were obtained with longer initial periods of exposure to acid, and with the higher concentration of acid. Samples of cotton freed of inorganic ions by this treatment yielded no measurable residue when ignited.

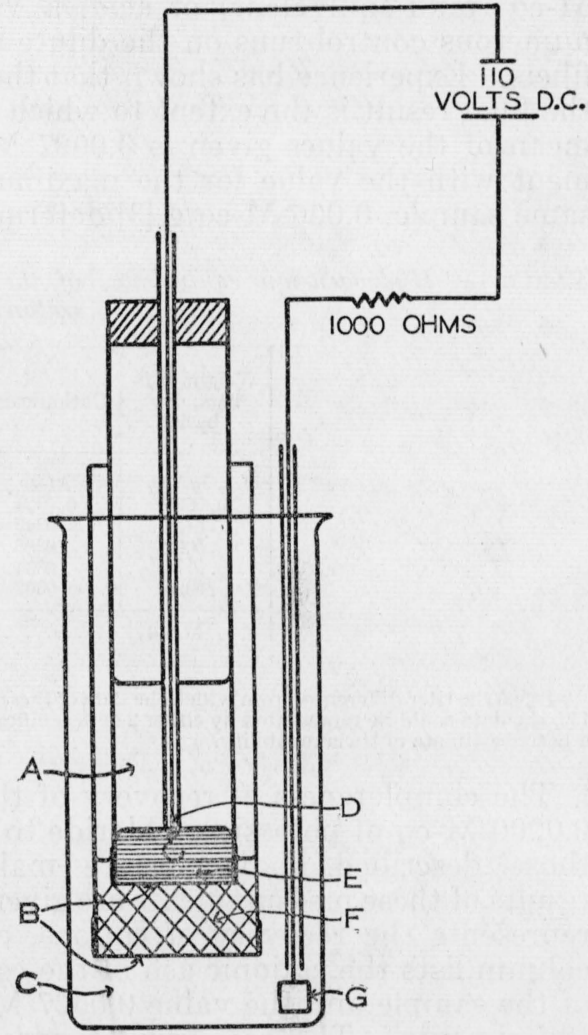

Figure 1.-Diagram of electrodialysis apparatus.

$A$, cathode vessel; $B$, Cellophane membranes; $C$, anode vessel; $D$, cathode; $E$, mercury; $F$, sample; $G$, anode

\section{RESULTS AND DISCUSSION}

\section{COTTON}

The cationic ash is a factor of primary importance in the behavior of naturally occurring cellulosic materials toward acids. Following the demonstration by McLean and Wooten that a linear relationship obtains between the contents of cationic ash and the acid-binding capacities of various cellulosic materials at an arbitrary $\mathrm{pH}$ [2], Sookne and Harris have shown that the limiting amount of acid with which cotton can be made to combine at low values of $\mathrm{pH}$ corresponds to the hydrogen-ion equivalence of its cationic ash [3]. The results of electrodialytic analysis of cotton may therefore be compared directly with the results obtained by an independent method. Table 
1 lists determinations of the cationic ash of a sample of dewaxed cotton, the preparation of which has been described elsewhere [3]. The values given have been corrected by subtracting a blank of 0.0040 M-eq (milli-equivalent) of acid, a value determined empirically by numerous control runs on the dilute acid solutions in the absence of fibers. Experience has shown that the major source of uncertainty in the final result is the extent to which the blank is reproducible. The mean of the values given is $0.0627 \mathrm{M}$-eq/g of cotton, in good agreement with the value for the maximum acid-binding capacity of the same sample, $0.066 \mathrm{M}$-eq/g [3] determined by direct titration.

TABLE 1.-Hydrogen-ion equivalence of the cationic ash of samples of dewaxed cotton

\begin{tabular}{|c|c|c|}
\hline $\begin{array}{c}\text { Weight of fi- } \\
\text { bers, dry } \\
\text { basis }\end{array}$ & Cationic ash & Cationic ash \\
\hline$g$ & $M-e q$ & $M-e q / g$ \\
0.5065 & 0.0324 & $\mathbf{0} 0.0640$ \\
.5159 & .0340 & .0659 \\
.5092 & .0305 & .0599 \\
.5176 & .0334 & .0645 \\
.5095 & .0302 & .0593 \\
\hline Mean & & 0.0627 \\
\hline
\end{tabular}

a Since the titer differences from which the data of these tables were computed had a precision of 1 part in 150 , the data could be represented by either 2 or 3 significant figures. They are given to 3 figures to permit a better estimate of their reliability.

The completeness of recovery of the cations was tested by adding $0.0200 \mathrm{M}$-eq of potassium chloride to weighed samples, identical with those described above, before making the determinations. The results of these measurements are given in table 2 . The second column represents the recovery of cations, combined plus added; the third column lists the cationic ash of the cotton calculated from the weight of the sample and the value $0.0627 \mathrm{M}$-eq/g obtained in the preceding experiments. The recovery of added potassium, shown in column 4 , is obtained by subtracting the figures of the third column from the corresponding figures of column 2. The resulting figures indicate very complete recovery of added potassium, and furnish strong evidence for the accuracy of the figures for the naturally occurring cations.

TABLE 2.-Recovery by electrodialysis of potassium ion added to samples of cotton

\begin{tabular}{|c|c|c|c|c|}
\hline $\begin{array}{c}\text { Weight of } \\
\text { fibers, dry } \\
\text { basis }\end{array}$ & $\begin{array}{c}\text { Total cati- } \\
\text { onic ash }\end{array}$ & $\begin{array}{c}\text { Cationic ash } \\
\text { of cotton }\end{array}$ & $\begin{array}{c}\mathrm{K}+, \text { recov- } \\
\text { ered }\end{array}$ & $\mathbf{K}+$, added \\
\hline g & $M-e q$ & $M-e q$ & $M-e q$ & $M-e q$ \\
0.5106 & 0.0519 & 0.0320 & 0.0199 & 0.0200 \\
.5115 & .0523 & .0321 & .0202 & .0200 \\
.5129 & .0525 & .0322 & .0203 & .0200 \\
\hline
\end{tabular}

\section{WOOL}

The ash content of samples of wool from different sources may vary over wide limits. A large part of the cation content of wool is combined with the acidic groups of the protein (as $R \mathrm{COO}^{-} M^{+}$). Consequently, close agreement between measurements of the amounts 
of acid bound by wool protein in different lots of wool at any given $\mathrm{pH}$ may only be achieved by subtracting the hydrogen-ion equivalent of the combined cations in each lot of wool from all directly determined values of the acid bound under any given conditions [4]. Thus a method is required for determining the equivalence of the ash rather than its weight percent, unless its composition is accurately known. Such a method, described in this paper, is also useful in wool processing, as for example in the control of neutralization and rinsing after the carbonization of wool.

Representative determinations of the ash of fibers, from two different sources, which had been extracted with alcohol and ether and washed with water are given in table 3 . It will be noted that longer intervals of time were employed than in the work with cotton. When appreciably shorter periods were allowed for soaking in acid, or for electrodialyzing, the resulting figures were lower and lacking in reproducibility. It has been shown that when wool is immersed in dilute solutions of acid the attainment of equilibrium requires much longer periods than when cotton fibers are similarly treated $[3,4]$. The shorter times sufficing for cotton are probably due to the fact that the greater part of the combined cations of dewaxed cotton are associated with an outer shell of pectic substance, which is more readily dissolved in dilute aqueous solutions than is the cellulosic part of the fiber, $[3,5,6]$. The longer interval required for complete ionic recoveries in the electrodialysis of wool is probably a consequence of the same factors which delay its attainment of equilibrium with solutions of acid.

TABLE 3.-Equivalence of the cationic ash in wool fibers

[ $3 \mathrm{ml}$ of $0.15 \mathrm{MHCl}$ were added to approximately $0.5 \mathrm{~g}$ of wool]

\begin{tabular}{|c|c|c|c|c|}
\hline $\begin{array}{c}\text { Time of } \\
\text { prelimi- } \\
\text { nary soak- } \\
\text { ing in acid }\end{array}$ & $\begin{array}{c}\text { Time of } \\
\text { passage of } \\
\text { current }\end{array}$ & $\begin{array}{c}\text { Cationic } \\
\text { ash }\end{array}$ & $\begin{array}{c}\text { Ash by } \\
\text { combus- } \\
\text { tion at } \\
700^{\circ} \mathrm{C}\end{array}$ & $\begin{array}{c}\text { Empirical } \\
\text { equivalent } \\
\text { weight of } \\
\text { ash }\end{array}$ \\
\hline & & & & \\
\hline$h r$ & $h r$ & $M-e q / g$ & $m g / g$ & $g$ \\
2.0 & 2.0 & 0.035 & 2.60 & 74.2 \\
2.0 & 2.0 & .029 & 2.60 & 89.5 \\
2.0 & 3.5 & .037 & 2.60 & 70.3 \\
1.5 & 4.3 & .036 & 2.60 & 72.2 \\
3.0 & 3.0 & .036 & 2.75 & 76.3 \\
3.0 & 3.0 & .151 & 11.4 & 75.5 \\
\hline
\end{tabular}

\footnotetext{
a In the course of this measurement, it was observed that the passage of current was impeded by the accumulation of gas bubbles. It seems likely that this observation explains the apparently incomplete recovery of combined cations in this single determination.
}

The empirical combining weights of the ash (milligrams of ash on ignition divided by milliequivalents of cations recovered on electrodialysis), are given in the last column of table 3. These have been calculated in order to provide a partial test of the reasonableness of the values obtained by electrodialysis and incidentally to determine approximate empirical factors for interconverting the quantities determined by electrodialysis and by combustion. The combining weights shown are somewhat higher than can be accounted for, if the ash is largely composed of the oxides of potassium, calcium, magnesium, iron, or aluminum, the combining weights of which are $47,28,20,26$, and 17, respectively. Since spectroscopic examination of the ignited residue indicated the presence of relatively large amounts of calcium, 
aluminum, and silicon, the average combining weight may be accounted for in part by the presence of silicates or of silicon dioxide, neither of which would affect the equilibria with dilute acids. In addition, part of the sulfur of the protein is oxidized to sulfate on ignition, and the weight of the ignited residue, and thus the empirical combining weight, is increased. The combining weights in the table are very close to those which would characterize the sulfates of the cations known to be present..$^{5}$ A comparison of the combining weights in the table with the combining weights calculated from the results of direct titration of the ignited residue with acid showed that less than half of the residue obtained after combustion was capable of combining with acid. This is consistent with the fact that a very large part of the ash is in the form of sulfate. The results tabulated also furnish a strong indication that the average combining weights of the ash from lots of wool characterized by widely different ash contents are sufficiently alike for these combining weights to be used as factors for interconverting the results which would be obtained by electrodialysis and by combustion.

An example of the manner in which the electrodialysis may be applied to routine mill analyses is given below. Both ash and cation determinations were made on pieces of undyed worsted and woolen cloths at different stages of the neutralization and rinsing processes directly following the carbonizing process. ${ }^{6}$ The results of these measurements are summarized in table 4.

TABLE 4.-Ash content of undyed pieces of wool cloth at various stages in processing

[Averages of three determinations on samples of $0.8 \mathrm{~g}$ soaked for 2 hours in $3 \mathrm{ml}$ of $0.15 \mathrm{M}$ hydrochloric acid and electrodialyzed for 2 hours]

\begin{tabular}{|c|c|c|c|c|}
\hline Nature of cloth & Stage in process & $\begin{array}{l}\text { Cationic } \\
\text { ash }\end{array}$ & $\begin{array}{l}\text { Ash by } \\
\text { combus- } \\
\text { tion at } \\
700^{\circ} \mathrm{C} \text {. }\end{array}$ & $\begin{array}{l}\text { Empirical } \\
\text { equivalent } \\
\text { weight of } \\
\text { ash }\end{array}$ \\
\hline $\begin{array}{l}\text { Lightly woven worsted } \\
\text { Do } \\
\text { Do }\end{array}$ & $\begin{array}{l}\text { Water-rinsed }{ }^{1} \\
\text { Soda-washed } \\
\text { Partially neutralized. }\end{array}$ & $\begin{array}{r}M-e q / g \\
0.025 \\
.439 \\
.071\end{array}$ & $\begin{array}{c}m g / g \\
0.65 \\
23.6 \\
5.0\end{array}$ & $\begin{array}{l} \\
26.0 \\
53.8 \\
70.8\end{array}$ \\
\hline Open weave, woolen and worsted & Water rinsed ${ }^{1}$ & .020 & .90 & 45.5 \\
\hline $\begin{array}{l}\text { combination. } \\
\text { Do } \\
\text { Do }\end{array}$ & $\begin{array}{l}\text { Soda-washed } \\
\text { "Completely neutralized" }\end{array}$ & $\begin{array}{l}.143 \\
.015\end{array}$ & $\begin{array}{l}8.15 \\
1.35\end{array}$ & $\begin{array}{l}57.0 \\
89.5\end{array}$ \\
\hline
\end{tabular}

1 These samples contained over 2 percent of sulfuric acid.

All the samples, including those which had been carbonized with sulfuric acid and then merely rinsed with water, contained a nonvolatile mineral residue. In those samples which were merely rinsed, this residue was so small as to render the calculated combining weights uncertain. However, the combining weights of the much larger amounts of ash obtained from the two samples treated with sodium carbonate are closely similar and are not far different from the combining weight of sodium carbonate, which is 53 . Owing to the large excess of ash in these samples over the amount of ash originally in

\footnotetext{
${ }^{5}$ Gravimetric analysis of some of the ashes reported in table 3 showed that 42 percent of their weight was $\mathrm{SO}_{4}$.

6 The authors are indebted to Werner von Bergen, Director of the Research and Control Laboratories, Forstmann Woolen Co., Passaic, N. J., for furnishing the samples used. A description of the stages in the neutralizing and rinsing process to which the table and text refer will be found in the American Wool Handbook, 1st edition, page 563 .
} 
untreated wool, the effects of the original ash on the average combining weight of these samples is practically negligible. Nevertheless, the close agreement between the experimental and theoretical combining weights of the ash of these samples may be in part coincidence. A considerable part of the carbonate originally present must, however, have been transformed into sodium sulfate by neutralization of sulfuric acid remaining on the cloth; if all of it were so transformed, the combining weight would have been 71 . It therefore appears likely that sulfates and oxides (formed by decomposition of carbonates, and from sodium ions combined with the wool itself) were present in addition to carbonate, with a resulting average equivalent weight close to the theoretical value for sodium carbonate. This suggestion receives some measure of support from the fact that a large part of the soda in the unburned sample had reacted with sulfuric acid and was present as sulfate. Thus only 0.24 millimole of acid per gram was required to neutralize the free base in a sample of the sodatreated cloth, although the total cation equivalence, as determined by electrodialysis, was 0.44 millimole, or almost twice as great.

As shown in table 4, the combining weights tend to rise after even partial neutralization and washing out of the soda-ash. On "complete neutralization" they rise still more. Since the "neutralized" material was low in ash before the soda treatment, the ash remaining after neutralization must have resulted largely from this treatment. The rise in the combining weight indicates that most of the carbonate, which would yield an ash of low combining weight, has been removed by washing, leaving sulfates of sodium and, to a much less extent, of other heavier ions initially in the fiber.

The feasibility of determining electrodialytically the sulfuric acid in the carbonized fibers, as distinguished from the sum of this quantity plus the sulfate formed in combustion, has been demonstrated in work with wool yarn previously treated with sulfuric acid. Samples of wool in the central chamber of the apparatus were immersed in $0.15 M$ sodium hydroxide and exposed to the passage of current for 4 hours. At the end of this period the contents of the anode chamber were analyzed gravimetrically for sulfate. The results agreed closely with similar sulfate analyses made on the total hydrolytic products of other samples of sulfuric-acid-treated wool which had been decomposed by hot concentrated hydrochloric acid.

By simultaneously measuring the hydrogen-ion equivalence of the cations and of sulfate and determining the difference between them, a figure of interest in mill technology, the content of excess acid or base may be obtained.

\section{ELECTRODIALYTIC DETERMINATION OF ACIDIC AND BASIC GROUPS OF FIBERS AND OTHER NONDIFFUSIBLE MATERIALS}

Application of the methods already described permits the estimation of the acidic or basic groups of substances which possess the following properties:

1. Nondiffusibility through Cellophane or collodion.

2. The capacity to form tightly bound complexes with at least one species of cation (for the estimation of acidic groups), or with at least one species of anion (for the estimation of basic groups). The complexes must not readily dissociate or hydrolyze on dialysis or washing 
sufficiently prolonged to remove the unbound excess of these ions. Such complexes are formed by calcium in the case of dewaxed cotton, and by various acid dyes in the case of protein substances [7].

3. A large difference between the strength of the acidic or basic groups to be estimated and the strengths of the other acidic or basic groups present. Thus, in cellulose, the estimation of the total number of carboxyl groups with calcium is possible only because these groups are very much more acidic than the hydroxyl groups; the latter do not combine with base under the conditions used.

The acidic (or basic) groups of substances which fulfill these three requirements may be determined by engaging the groups with a suitable cation (or anion) by treatment with a suitable base (or acid), removing the excess reagent by washing (if the product is insoluble) or dialyzing (if the product is soluble), and electrodialyzing to determine the amount of cation (or anion) remaining combined.

In order to illustrate the application of the above general procedure, the determination of the acidic groups of cotton is described below.

Table 5 gives data for the cationic ashes of samples of dewaxed cotton which had been soaked in limewater for 3 hours, and washed with running distilled water for 24 hours. Comparison of these results with those of table 1 shows that the limewater treatment does not increase the cationic ash of dewaxed cotton appreciably. It has been stated in section III-1 that the hydrogen-ion equivalence of the cationic ash of dewaxed cotton corresponds closely with the number of carboxyl groups as determined by an independent method, the direct titration of these groups with acid. It therefore follows that the cationic ash of lime-washed dewaxed cotton is a measure of the total number of carboxyl groups of the fiber and, further, that the carboxyl groups of unprocessed cotton are almost entirely present as the carboxylates of various tightly bound ions [3].

TABLE 5.-Hydrogen-ion equivalence of the cationic ash of lime-washed, dewaxed cotton

\begin{tabular}{|c|c|c|}
\hline $\begin{array}{l}\text { Weight } \\
\text { of fibers, }\end{array}$ & \multicolumn{2}{|c|}{ Cationic ash } \\
\hline $\begin{array}{r}g \\
0.749 \\
.776 \\
.780\end{array}$ & $\begin{array}{c}M-e q \\
0.0474 \\
.0500 \\
.0506\end{array}$ & $\begin{array}{r}M-e q / g \\
0.0633 \\
.0644 \\
.0649\end{array}$ \\
\hline \multicolumn{2}{|c|}{ Mean.. } & 0.0642 \\
\hline
\end{tabular}

The method has also been applied to the measurement of the acidic groups of depectinized cotton. The material was prepared by the modification of the American Chemical Society procedure for the purification of cotton described by Worner and Mease [8]. This procedure involves the extraction of the fibers with a boiling 1-percent solution of sodium hydroxide. At a later stage in the process the fibers are thoroughly washed with a 1-percent solution of acetic acid, a treatment which undoubtedly removes some of the cations initially combined with the fiber or taken up from the basic solution. In order to replace cations on the carboxyl groups, the samples were soaked in a saturated solution of calcium hydroxide for 3 hours and 
washed with running distilled water for 24 hours. The results of determinations of the cationic ashes of these samples are given in table 6 . Samples 1 to 4 were extracted with alkali for 4 hours, and had a maximum acid-binding capacity of $0.008 \mathrm{M}$-eq/g. Samples 5 and 6 were extracted with alkali for 8 hours, and had a maximum acid-binding capacity of $0.009 \mathrm{M}-\mathrm{eq} / \mathrm{g}$ [3]. The data show the close correspondence between the carboxylate content and the hydrogen-ion equivalence of the cationic ash.

TABLE 6.-Hydrogen-ion equivalence of the cationic ash of lime-washed depectinized cotton

\begin{tabular}{|c|c|c|c|}
\hline Sample number & $\begin{array}{l}\text { Weight of } \\
\text { fibers, dry }\end{array}$ & \multicolumn{2}{|c|}{ Cationic ash } \\
\hline $\begin{array}{l}1 \\
2 \\
3 \\
4\end{array}$ & $\begin{array}{c}g \\
0.5168 \\
.7063 \\
.8775 \\
.754\end{array}$ & $\begin{array}{c}M-e q \\
0.0054 \\
.0067 \\
.0079 \\
.0069\end{array}$ & $\begin{array}{r}M-e q / g \\
\mathrm{a} 0.0104 \\
.0095 \\
.0090 \\
.0092\end{array}$ \\
\hline Mean_......... & (n) & - n & 0.0095 \\
\hline 6 & $\begin{array}{l}746 \\
731\end{array}$ & $\begin{array}{l}.0080 \\
.0067\end{array}$ & $\begin{array}{r}0.0107 \\
.0090\end{array}$ \\
\hline Mean & 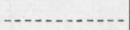 & - non & 0.0099 \\
\hline
\end{tabular}

a Since the titer differences from which the data of these tables were computed had a precision of 1 part in 25 , the data could be represented either as shown, or by one less significant figure. They are given as shown to permit a better estimate of their reliability.

\section{REFERENCES}

[1] N. R. Joseph and W. C. Stadie, J. Biol. Chem. 125, 795 (1938).

[2] D. A. MeLean and L. A. Wooten, Ind. Eng. Chem. 31, 1138 (1939).

[3] A. M. Sookne and M. Harris. J. Research NBS 25, 47 (1940) RP1313.

[4] J. Steinhardt and M. Harris, J. Research NBS 24, 335 (1940) RP1286; Am. Dyestuff Reptr. 29, 103, 131 (1940); Textile Research 10, 181 (1940).

[5] R. L. Whistler, A. R. Martin, and M. Harris. [In preparation.]

[6] C. W. Hock and M. Harris. [In preparation.]

[7] J. Steinhardt and M. Harris. J. Biol. Chem. 133, 97 (1940).

[8] R. K. Worner and R. T. Mease, J. Research NBS 21, 609 (1938) RP1146.

Washington, April 4, 1940. 